\title{
Improving evidence informed policy-making for health in the Eastern Mediterranean Region
}

\author{
Arash Rashidian ', Ahmed Mandil' ${ }^{1}$ and Jaouad Mahjour ${ }^{2}$
}

Health policies should be based on a sound understanding of the problems, issues and context in which they operate, for which they require reliable data and information for action $(1,2)$. The policies should also be informed by the best available research evidence (3), which also helps in better capturing the problem, understanding existing trends and patterns, and setting reasonable objectives that can be achieved using effective interventions. More importantly, research can provide evidence of comparative effectiveness of alternative interventions for a given public health issue; the costs and feasibility of implementing each intervention; and efficiency of the proposed interventions (policies) in comparison with alternative interventions. These arguments apply whether we are considering national policies or focusing on policies developed or advocated through international organizations, including the World Health Organization (WHO) $(4,5)$.

In the Eastern Mediterranean Region (EMR), three parallel streams have shaped, and continue to shape, use of research evidence in health policies. First, there has been a growing interest in the use of research evidence in health policies. The increasing demand for research evidence has followed national discourse in many countries, where public policies -including health policies - are increasingly assessed in a critical way (6-9). In recent years, health concerns are prominently featured in political debates and national discourse in several countries. This level of scrutiny had made it important for the politicians to demonstrate how they develop prudent policies, and the effects of such policies on health outcomes. Also, increasing population demand for health services and aging populations have resulted in increasing health care costs, resulting in closer scrutiny of health policies. Moreover, such conditions have also meant that ministries of health are having more success in putting 'health' on the agenda of policy-makers outside the health sector. With increasing focus on social determinants of health, and now the Social Development Goals as a global agenda (10), health is more featured in the political discussions and hence, further demand to support health policy decisions with research evidence.

The second stream is related to availability, validity and relevance of research evidence for health policymaking. Different assessments have demonstrated a considerable increase in the number of research outputs from the countries of the region. While this trend started from a handful of countries in the last decade, it has affected more countries in the Region (11). This is important as this may partially alleviate a major concern related to use of research evidence in decision-making. The policy-makers' concern has traditionally related to the fact that most research evidence presented to them actually originated from high-income countries beyond the Region, which have a different set of priorities, challenges and decision-making processes. Hence, policy-makers perceived research evidence presented to them as irrelevant to their context (12). With more research originating from the Region, this picture is about to change. At the same time, regional output on research is challenged from two fronts. Over the last decade, five countries of the Region produced $80 \%$ of regional research output in terms of peer-reviewed publications. More noteworthy, the three leading universities of the Region published over $10 \%$ of the total papers published in indexed journals (11). The other relevant challenge is related to the quality of research from the Region, and its attention to public health issues (13). In both fronts, there has been some progress, but there remain important limitations.

The third stream is related to the institutional capacity of the ministries of health (and other related public institutions) in retrieving, assessing and using research evidence. While there are many more 'decision-oriented' research studies being published every year (e.g. systematic reviews), systematically using such evidence in decision-making processes requires a level of institutional capacity and technical expertise that many ministries of health may lack. Also, technical expertise on its own may not be sufficient for the expectations and processes of decision-making. Over the years, WHO has advocated different structural approaches and technical solutions for further use of research evidence in formulating key decisions. Health Technology Assessment programmes, and national plans for adoption or development of clinical 
public health guidelines are among these (14). So far the progress on both fronts has been limited in the Region, as few countries have established such mechanisms at the national level (15). WHO also advocates development of policy briefs for key policy decisions (16). Policy briefs can improve the transparency of decision-making in health, as well as bringing forward benefits and challenges that might be faced if policy-makers adopt one course of action instead of others.

In summary, there is a strong political will in the EMR to enhance use of research evidence in decisionmaking. This was demonstrated in the Eastern Mediterranean Regional Committee Resolution EM/RC64/R.1
(Islamabad, Pakistan; October 2017)1, in which ministers of health committed themselves to "take necessary action towards conducting public health research that is directed towards the requirements of health services and that addresses people's health needs; and build national capacity to use evidence from health research in national policy-making for health". The Member States also requested WHO to "establish regional mechanisms to support the bridging of gaps between relevant research institutions and policy-makers and the translation of research evidence into health policy statements, and support the establishment of national mechanisms."
To materialize these commitments, systematic programmes are required to identify the priority health topics, establish research evidence review processes, and develop decision-making approaches that require the consideration of research evidence. While these may sound difficult to a country with limited past experience or with complex decision-making processes, in practice there might be effective approaches that work for different scenarios with different levels of capacity within the countries. WHO is committed to supporting countries in their objective of improving health-related policies, and ultimately improving health outcomes, through evidence informed policy-making.

\section{References}

1. Alwan A, Ali M, Aly E, Badr A, Doctor H, Mandil A, et al. Strengthening national health information systems: challenges and response. East Mediterr Health J. 201602 1;22(11):840-50. https://doi.org/10.26719/2016.22.11.840 PMID:28177115

2. Eastern Mediterranean Region Framework for health information systems and core indicators for monitoring health situation and health system performance. Cairo: WHO Regional Office for the Eastern Mediterranean; 2017.

3. World Health Organization. The WHO strategy on research for health. Geneva: World Health Organization; 2012.

4. World Health Report 2013. Research for universal health coverage. Geneva: World Health Organization; 2013 (http:// www.who.int/whr/2013/report/en/).

5. Rashidian A. Policy and programme evaluation: principles and objectives. East Mediterr Health J. 201702 21;23(1):3-4. https:// doi.org/10.26719/2017.23.1.3 PMID:28244054

6. Haq Z, Hafeez A, Zafar S, Ghaffar A. Dynamics of evidenceinformed health policy making in Pakistan. Health Policy Plan. 2017 Dec 1;32(10):1449-56. https://doi.org/10.1093/heapol/ CZx128 PMID:29045672

7. Al Mawali AHN, Al Qasmi AM, Al Sabahi SMS, Idikula J, Elaty MAA, Morsi M, et al. Oman Vision 2050 for Health Research: A Strategic Plan for the Future Based on the Past and Present Experience. Oman Med J. 2017 Mar;32(2):86-96. https://doi. org/10.5001/omj.2017.18 PMID:28439378

8. Imani-Nasab MH, Seyedin H, Yazdizadeh B, Majdzadeh R. A qualitative assessment of the evidence utilization for health policy-making on the basis of SUPPORT tools in a developing country. Int J Health Policy Manag. 201701 8;6(8):457-65. https://doi.org/10.15171/ijhpm.2016.158 PMID:28812845

9. El-Jardali F, Lavis JN, Ataya N, Jamal D, Ammar W, Raouf S. Use of health systems evidence by policymakers in eastern
Mediterranean countries: views, practices, and contextual influences. BMC Health Serv Res. 2012 07 16;12(1):200. https:// doi.org/10.1186/1472-6963-12-200 PMID:22799440

10. World Health Organization. Health in 2015: from MDGs to SDGs. Geneva: World Health Organization; 2015 (http:// www.who.int/gho/publications/mdgs-sdgs/en/).

11. Tadmouri GO, Mandil A, Rashidian A. Development of an Eastern Mediterranean Region search strategy for biomedical citations indexed in PubMed. East Mediterr Health J. 2017 11 19;23(9):619-29. https://doi.org/10.26719/2017.23.9.619 PMID:29178119

12. Yousefi-Nooraie R, Rashidian A, Nedjat S, Majdzadeh R, Mortaz-Hedjri S, Etemadi A, et al. Promoting development and use of systematic reviews in a developing country. J Eval Clin Pract. 2009 Dec;15(6):1029-34. https://doi.org/10.1111/j.13652753.2009.01184.x PMID:20367702

13. Rashidian A, Jahanmehr N, Jabbour S, Zaidi S, Soleimani F, Bigdeli M. Bibliographic review of research publications on access to and use of medicines in low-income and middleincome countries in the Eastern Mediterranean Region: identifying the research gaps. BMJ Open 2013;3:10 e003332. https://doi.org/10.1136/bmjopen-2013-003332.

14. World Health Organization. WHO handbook for guideline development. 2nd ed. Geneva: World Health Organization; 2014.

15. World Health Organization. 2015 Global Survey on Health Technology Assessment by National Authorities. Main findings. Geneva: World Health Organization; 2015.

16. World Health ORanization. SURE guides for preparing and using evidence-based policy briefs. Version 2.1. Geneva: World Health Organization; 2011 (http://www.who.int/ evidence/sure/guides/en/).

\footnotetext{
Regional Committee for the Eastern Mediterranean. Sixty-fourth Session RCl/64 (http://applications.emro.who.int/docs/RC_ technical_papers_20094_1_2017_en.pdf?ua=1).
} 